\title{
Prevalence of osteoporosis and its associated factors in older adult's users of the Primary Health Care
}

\author{
Prevalência de osteoporose e seus fatores associados em idosos usuários da Atenção \\ Primária à Saúde
}

\section{AUTHOR'S \\ Daniel Vicentini de Oliveira ${ }^{1}$ (D) \\ Gustavo Vinicius do Nascimento de Oliveira ${ }^{2}$ \\ Diogo Alves da Silva² \\ Naelly Renata Saraiva Pivetta ${ }^{1}$ \\ Mateus Dias Antunes ${ }^{3}$ (D) \\ José Roberto Andrade do Nascimento Júnior ${ }^{4}$ (it) \\ Cláudia Regina Cavaglieri ${ }^{5}$ \\ 1 Universidade Estadual de Campinas, \\ Departamento de Pós-graduação em Gerontologia, \\ Campinas, São Paulo, Brasil. \\ 2 Centro Universitário Metropolitano de Maringá, \\ Departamento de Graduação em Educação Física, \\ Maringá, Paraná, Brasil. \\ 3 Centro Universitário de Maringá, Departamento \\ de Pós-graduação em Promoção da Saúde, Maringá, \\ Paraná, Brasil. \\ 4 Universidade Federal do Vale do São Francisco, \\ Departamento de Graduação em Educação Física, \\ Petrolina, Pernambuco, Brasil. \\ 5 Universidade Estadual de Campinas, \\ Departamento de Pós-graduação em Gerontologia, Campinas, São Paulo, Brasil.}

\section{CORRESPONDING}

Daniel Vicentini de Oliveira

d.vicentini@hotmail.com

Avenida Londrina, 934, Apartamento 1907,

torre A. Maringá, Paraná, Brasil.

CEP: 87050-730.

DOI

$10.12820 /$ rbafs. $23 \mathrm{e} 0055$

\section{(cc) BY-NC-SA}

This work is licensed under the Creative Commons Attribution-NonCommercial-ShareAlike 4.0 International License

\begin{abstract}
This study examine the prevalence and factors associated to osteoporosis among older adults users of the primary health care. This cross-sectional study was carried out with 654 older adults $56 \%$ women) from primary health care in Maringá, Paraná, Brazil. The instruments used were the sociodemographic questionnaire and the International Physical Activity Questionnaire (IPAQ), short version. Data analysis was conducted through Chi-square test and Binary Logistic Regression $(\mathrm{p}<0.05)$. The results showed a prevalence of $15.6 \%$ of older adults who reported the presence of osteoporosis. There was a higher prevalence of women with osteoporosis $(\mathrm{p}=0.001)$, and on the other hand, there was a greater proportion of married elderly individuals $(p=0.003)$, and elderly with income above three minimum wages $(\mathrm{p}=0.020)$ with absence of osteoporosis. The results showed that women (OR $=4.45 ; 95 \% \mathrm{CI}: 2.47-8.01)$ and the older adults who take more than two medications $(\mathrm{OR}=1.67$; 95\%CI: 1.15-2.42) were more likely to present osteoporosis. Older adults who presented a history of falls are $47.0 \%$ more likely to present osteoporosis. It was concluded that sex, the amount of medications and the history of falls are associated with the prevalence of osteoporosis in the older adults.

Keywords: Aging; Health; Older adults; Osteoporosis; Motor activity; Unified Health System.

RESUMO

Este estudo analisou os fatores associados a prevalência de osteoporose em idosos usuários da Atenção Primária à Saúde. Estudo transversal, realizado com 654 idosos (56\% mulheres) da Atenção Primária à Saúde de Maringá, Paraná, Brasil. Os instrumentos utilizados foram o questionário sociodemográfico e o Questionário internacional de atividade física (IPAQ), versão curta. A análise dos dados foi realizada por meio do teste Qui-quadrado e Regressão Logística Binária $(p<0,05)$. Os resultados mostraram uma prevalência de $15,6 \%$ de idosos que relataram a presença de osteoporose. Houve maior prevalência de mulheres com osteoporose $(p=0,001)$ e, por outro lado, houve maior proporção de idosos casados $(p=0,003)$ e idosos com renda acima de três salários mínimos $(p=0,020)$ com ausência de osteoporose. Os resultados mostraram que as mulheres $(O R=4,45 ; I C 95 \%: 2,47-8,01)$ e os idosos que tomam mais de dois medicamentos $(O R=1,67$; IC95\%: 1,15-2,42) foram mais propensos a apresentar osteoporose. Concluiu-se que o sexo, a quantidade de medicamentos e a história de quedas estão associados à prevalência de osteoporose em idosos.
\end{abstract}

Palavras-chave: Envelhecimento; Saúde do idoso; Osteoporose; Atividade motora; Sistema Único de Saúde.

\section{Introduction}

Osteoporosis is a skeletal disorder that predisposes to bone fracture ${ }^{1}$. It is characterized by reduction of bone mineral density ${ }^{2}$. It predominantly affects postmenopausal women and elderly people ${ }^{2,3}$. Several factors can contribute to the occurrence of osteoporosis, among them: family history, Caucasian and Asian ethnicity, smoking habit, early menopause, low body mass index, and low calcium intake ${ }^{4}$.

Osteoporosis usually has no clinical manifestations and is often diagnosed late after a low-impact fracture episode $^{3}$. This is among the main causes of fracture in 
the elderly population and generates a negative economic impact on public health, increasing morbidity and mortality rates ${ }^{2,3,5}$. Proper management of osteoporosis suggests improved quality of life and reduced risk of fractures and includes pharmacological treatment, calcium-rich diet, vitamin D replacement, and regular physical exercise ${ }^{3}$. Surveillance and monitoring studies in physical activity have pointed to high prevalence's of physical inactivity in the elderly in different regions of the world, such as Australia4.

In order to promote health, prophylaxis of diseases, treatment and rehabilitation, Basic Health Units (BHUs) seek to provide comprehensive care for the health of users, including the management of pathologies such as osteoporosis ${ }^{6}$. Considering the prevalence of osteoporosis in the elderly population and its negative repercussion on health, this study aimed analyze the factors associated to the prevalence of osteoporosis among elderly users of the primary health care.

\section{Methods}

The sampling process of this cross-sectional epidemiological study was performed in two stages. Initially the BHUs in the four regions of the city were listed: East (seven BHUs), covering $21.8 \%$ of the population; North (eight BHUs), covering 34.5\% of the population, West (eight BHUs); covering 23.2\% of the population and South (8 BHUs); covering $20.4 \%$ of the total elderly population. Three of the BHUs of each geographic region were randomly selected to participate in the study, totaling $12 \mathrm{BHUs}$. According to data from the Health Department of Maringá, Paraná, in 2016, approximately 42,000 elderly people are assisted in the BHUs of the municipality. From this target population, and taking into account the possible sample losses, the sample size of 654 elderly individuals, who were selected for convenience, was established. A confidence level of $95 \%$ and $4 \%$ of margin of error was adopted and the software used to obtain the calculations was the StatDisk version 8.4.

Elderly people of both genders aged 60 years and over, with preserved speech and hearing capacity, and who agreed to respond to the questionnaires were included in the study. Elderly individuals with possible cognitive deficits as evaluated through the Mini Mental State Examination (MMSE) ${ }^{7}$ were excluded. The cut-off scores used for exclusion by the MMSE were: 17 for illiterate elderly; 22 for elderly people with 1 to 4 years of schooling; 24 for those with 5 to 8 years schooling; and 26 for those with 9 years or more of schooling. These values correspond to the average obtained by these authors ${ }^{8}$ for each schooling range, subtracted from one standard deviation. Elderly participants classified below the cut-off point specific to their schooling level were excluded from the study. Data were obtained from the elderly who were present in the waiting rooms of each Basic Health Unit. After applying the exclusion criteria, 31 elderly were excluded.

A semi-structured questionnaire was used for characterization of the sociodemographic and health profile, covering information on gender, age, civil status, monthly income in minimum wages (MW), retirement, health perception, smoking, history of falls and near falls in the last semester, and associated comorbidities. The presence/absence of osteoporosis was evaluated through self-report of the elderly.

The level of physical activity of the elderly was evaluated using the International Physical Activity Questionnaire - short form (IPAQ) This instrument is composed of seven open questions and the information allows to estimate the time spent per week in different dimensions of physical activity (moderate and vigorous walking and physical exertion) and physical inactivity (sitting position). According to the level of physical activity, the participants were classified as sedentary, irregularly active, active or very active. Sedentary behavior was estimated based on the average sitting time a typical weekday and on a typical weekend day ${ }^{9,10}$.

Initially, the Assistance Service for Permanent Training and Qualification of Health Workers (CECAPS) was contacted to request authorization for data collection. The research project was approved by the Research Ethics Committee of the University Center of Maringá (UNICESUMAR) through Opinion 1.626.966/2016, according to the norms of Resolution 466/12 of the National Health Council on research involving humans.

The elderly volunteers were approached by the researchers and informed about the justification, objectives and procedures to be performed. After these procedures, those who accepted to participate in the research signed the Informed Consent Term (ICT). The collection was carried out within a couple of days, in different shifts and hours according to the availability of the researchers. We opted for direct interview for application of the questionnaires due to the possible difficulty of reading, visual problems, and comprehension of the questions.

The analysis used a descriptive and inferential sta- 
tistical approach. Frequency and percentage were used as descriptive measures for categorical variables. For inferential analyses, the chi-square test was used to investigate the difference in the incidence of osteoporosis as a function of sociodemographic variables and health conditions of the elderly. Binary Logistic Regression (crude and adjusted analysis) was used to examine the associations of sociodemographic variables and health conditions (independent variables) with the presence of osteoporosis (dependent variable) in the elderly. Only variables with a level of significance equal to or less than 0.20 in the chi-square test were included in the regression. The goodness of fit of the model was verified through the Hosmer-Lemeshow test. All variables were included in the adjusted analysis, regardless of the p-value found in the crude analysis. A hierarchical approach was adopted in the adjusted analysis, with backward approach of variables in the models. A p-value of less than 0.20 was used as criterion for retention of the factor in the adjusted regression model. At the end, a final regression model was run exclusively with the variables of greater statistical significance. A significance level of $\mathrm{p}<$ 0.05 and a $95 \%$ confidence interval (CI) were adopted in the analyses, and adjusted odds ratios were calculated.

\section{Results}

Among the 654 elderly people evaluated, there was a predominance of female gender (56.0\%), married status (61.3\%), ages from 60 to 69 years (59.2\%), monthly income from 1 to 2 minimum wages (70.0\%), people who never smoked (56.6\%), white race (81.0\%) and retired elderly (75.0\%). It was also observed that the majority of the elderly had incomplete elementary education (43.0\%). Regarding the health profile of the elderly users of primary health care in the city of Maringá, it was verified that the majority of the elderly had good perception of health (48.5\%), took 1 to 2 medications regularly (43.9\%), had no history of falls $(83.7 \%)$ or near falls in the last six months (79.7\%) and was physically active/very active (60.7\%). It was also noted that most of the elderly reported 1 to 2 associated comorbidities (50.5\%). There was also a prevalence of $15.6 \%$ of elderly who reported the presence of osteoporosis.

There was a significant difference between sexes, marital status and monthly income when comparing the proportions of the elderly with and without osteoporosis according to socio-demographic variables ( $\mathrm{Ta}-$ ble 1). These results indicated that there was a higher prevalence of women with osteoporosis, and on the other hand, there was a greater proportion of married elderly individuals, and elderly with income above three minimum wages with absence of osteoporosis.

Table 1 - Comparison of the proportions of elderly people with and without osteoporosis among users of the primary health care, according to sociodemographic variables and health conditions.

Maringá, Paraná, Brazil, 2018 ( $\mathrm{n}=654)$.

\begin{tabular}{|c|c|c|c|c|}
\hline \multirow{3}{*}{ Variables } & \multicolumn{2}{|c|}{ Osteoporosis } & \multirow{3}{*}{$\chi^{2}$} & \multirow{3}{*}{$\mathrm{P}$} \\
\hline & Yes & No & & \\
\hline & $\mathrm{n}(\%)$ & $\mathrm{n}(\%)$ & & \\
\hline \multicolumn{5}{|l|}{ Sex } \\
\hline Male & $15(5.2)$ & $273(94.8)$ & 42.379 & $0.001^{*}$ \\
\hline Female & $87(23.8)$ & $278(76.2)$ & & \\
\hline \multicolumn{5}{|l|}{ Age group } \\
\hline 60 to 69 years & $68(17.6)$ & $319(82.4)$ & & \\
\hline 71 to 79 years & $26(13.3)$ & $170(86.7)$ & 2.747 & 0.097 \\
\hline 80 years or more & $8(11.4)$ & $62(88.6)$ & & \\
\hline \multicolumn{5}{|l|}{ Marital status } \\
\hline Married & $49(12.2)$ & $352(87.8)$ & 9.060 & $0.003^{*}$ \\
\hline Single & $13(22.4)$ & $45(77.6)$ & & \\
\hline Divorced/separated & $11(14.9)$ & $63(85.1)$ & & \\
\hline Widow/widower & $29(24.2)$ & $91(75.8)$ & & \\
\hline \multicolumn{5}{|l|}{ Race } \\
\hline White & $89(16.8)$ & $440(83.2)$ & 3.518 & 0.061 \\
\hline Black & $12(11.4)$ & $93(88.6)$ & & \\
\hline Others & $1(5.3)$ & $18(94.7)$ & & \\
\hline \multicolumn{5}{|l|}{ Schooling } \\
\hline Illiterate & $15(19.0)$ & $64(81.0)$ & 0.116 & 0.734 \\
\hline Incomplete primary school & $40(14.3)$ & $240(85.7)$ & & \\
\hline Complete primary school & 27 (18.4) & $120(81.6)$ & & \\
\hline Complete secondary school & $11(11.5)$ & $85(88.5)$ & & \\
\hline Higher education & $9(17.6)$ & $42(82.4)$ & & \\
\hline \multicolumn{5}{|l|}{ Smoking } \\
\hline Yes & $8(12.3)$ & $57(87.7)$ & & \\
\hline No, I've never smoked & 69 (18.6) & $301(81.4)$ & 1.459 & 0.227 \\
\hline No, but I used to be smoker & $25(11.5)$ & $193(88.5)$ & & \\
\hline \multicolumn{5}{|l|}{ Retirement } \\
\hline Yes & $68(14.0)$ & $416(86.0)$ & 1.884 & 0.170 \\
\hline No & $30(18.5)$ & $132(81.5)$ & & \\
\hline \multicolumn{5}{|l|}{ Monthly income } \\
\hline 1 to $2 \mathrm{MW}$ & $75(17.4)$ & $357(82.6)$ & 5.426 & $0.020^{*}$ \\
\hline 2.1 to $3 \mathrm{MW}$ & $17(10.9)$ & $139(89.1)$ & & \\
\hline More than $3 \mathrm{MW}$ & $2(6.7)$ & $28(93.3)$ & & \\
\hline \multicolumn{5}{|l|}{ Perception of health } \\
\hline Good & $36(11.4)$ & $280(88.6)$ & 12.343 & $0.001^{*}$ \\
\hline Regular & $46(17.6)$ & $216(82.4)$ & & \\
\hline Poor & $20(27.4)$ & $53(72.6)$ & & \\
\hline \multicolumn{5}{|l|}{ Reason of the visit to the $\mathrm{BHU}$} \\
\hline Medical visit & $52(17.9)$ & $239(82.1)$ & & \\
\hline Collect medications & $31(14.6)$ & $182(85.4)$ & 1.890 & 0.169 \\
\hline Make tests & 19 (13.1) & $126(86.9)$ & & \\
\hline
\end{tabular}

Continue... 
... continue

\begin{tabular}{|c|c|c|c|c|}
\hline \multirow{3}{*}{ Variables } & \multicolumn{2}{|c|}{ Osteoporosis } & \multirow{3}{*}{$\chi^{2}$} & \multirow{3}{*}{$\mathrm{P}$} \\
\hline & Yes & No & & \\
\hline & $\mathrm{n}(\%)$ & $\mathrm{n}(\%)$ & & \\
\hline \multicolumn{5}{|l|}{ Medications } \\
\hline None & $8(8.3)$ & $88(91.7)$ & & \\
\hline 1 to 2 & $32(11.2)$ & $253(88.8)$ & 17.371 & $0.001^{*}$ \\
\hline More than 2 & $62(23.2)$ & $205(76.8)$ & & \\
\hline \multicolumn{5}{|l|}{ Falls } \\
\hline Yes & $29(27.4)$ & $77(72.6)$ & 13.096 & $0.001^{*}$ \\
\hline No & $73(13.4)$ & $472(86.6)$ & & \\
\hline \multicolumn{5}{|l|}{ Near falls } \\
\hline Yes & $32(24.2)$ & $100(75.8)$ & 9.153 & $0.002 *$ \\
\hline No & $70(13.5)$ & $448(86.5)$ & & \\
\hline \multicolumn{5}{|c|}{ Level of physical activity } \\
\hline Very active/active & $65(16.4)$ & $332(83.6)$ & & \\
\hline Irregularly active & $25(14.0)$ & $154(86.0)$ & 0.217 & 0.641 \\
\hline Sedentary & $12(15.6)$ & $65(84.4)$ & & \\
\hline
\end{tabular}

* Significant association $=\mathrm{p}<0.05$; Chi-square test for proportions; $\mathrm{MW}=$ minimun wage; $\mathrm{BHU}=$ Basic Health Unic.

The comparison of proportions of elderly people with and without osteoporosis as a function of health conditions (Table 1) showed a significant difference with perception of health, use of medication and history of falls and near falls. These results show that there seems to be an association of good health perception, non-intake of medications, absence of falls in the last 6 months and no history of falls and near falls with the absence of osteoporosis.

Only variables with a level of significance equal to or less than 0.20 in the chi-square test were included in the regression. Table 2 shows the sociodemographic factors associated with the presence of osteoporosis. In the crude analysis, there was a significant association between presence of osteoporosis and gender, marital status, perception of health, use of medication, and occurrence of falls and near falls.

When the analysis was adjusted for all variables, gender, use of medication and history of falls remained associated with osteoporosis. It should be pointed out that women $(\mathrm{OR}=4.45 ; 95 \% \mathrm{CI}: 2.47-8.01)$ and the elderly who take more than two medications $(\mathrm{OR}=$ 1.67; 95\%CI: $1.15-2.42$ ) were more likely to present osteoporosis when compared to men and elderly people who do not take medicines. On the other hand, history of falls (yes) was observed as a protection factor; the elderly who presented a history of falls in the last six months are $47.0 \%$ more likely to present osteoporosis than the elderly who did not report falls.
Table 2 - Factors associated with the presence of osteoporosis among elderly users of the primary health care. Maringá, Paraná, Brazil, 2018 ( $\mathrm{n}=654)$.

\begin{tabular}{|c|c|c|}
\hline Variables & $\mathrm{OR}_{\text {crude }}$ & $\mathrm{OR}_{\text {adiusted }}(95 \% \mathrm{CI})$ \\
\hline \multicolumn{3}{|l|}{ Sex } \\
\hline Male & 1.00 & 1.00 \\
\hline Female & $5.6(3.2-10.1)^{*}$ & $4.4(2.4-8.0)^{*}$ \\
\hline \multicolumn{3}{|l|}{ Age group } \\
\hline 60 to 69 years & 1.00 & \\
\hline 71 to 79 years & $0.7(0.4-1.1)$ & \\
\hline 80 years or more & $0.6(0.2-1.3)$ & \\
\hline \multicolumn{3}{|l|}{ Marital status } \\
\hline Married & 1.00 & \\
\hline Single & $2.0(1.0-4.1)^{*}$ & \\
\hline Divorced/separated & $1.2(0.6-2.5)$ & \\
\hline Widow/widower & $2.2(1.3-3.8)^{*}$ & \\
\hline \multicolumn{3}{|l|}{ Race } \\
\hline White & 1.00 & \\
\hline Black & $0.6(0.3-1.2)$ & \\
\hline Others & $0.2(0.0-2.0)$ & \\
\hline \multicolumn{3}{|l|}{ Retirement } \\
\hline Yes & 1.00 & \\
\hline No & $1.3(0.8-2.2)$ & \\
\hline \multicolumn{3}{|l|}{ Monthly income } \\
\hline 1 to $2 \mathrm{MW}$ & 1.00 & \\
\hline 2.1 to $3 \mathrm{MW}$ & $0.5(0.3-1.0)$ & \\
\hline More than $3 \mathrm{MW}$ & $0.3(0.0-1.4)$ & \\
\hline \multicolumn{3}{|l|}{ Perception of health } \\
\hline Good & 1.00 & \\
\hline Regular & $1.6(1.0-2.6)^{*}$ & \\
\hline Poor & $2.9(1.5-5.4)^{*}$ & \\
\hline \multicolumn{3}{|l|}{ Medications } \\
\hline None & 1.00 & \\
\hline 1 to 2 & $1.3(0.6-3.1)$ & \\
\hline More than 2 & $3.3(1.5-7.2)^{*}$ & $1.6(1.1-2.4)^{*}$ \\
\hline \multicolumn{3}{|l|}{ Falls } \\
\hline Yes & 1.00 & 1.00 \\
\hline No & $0.4(0.2-0.6)^{*}$ & $0.5(0.3-0.9)^{*}$ \\
\hline \multicolumn{3}{|l|}{ Near falls } \\
\hline Yes & 1.00 & 1.00 \\
\hline No & $0.4(0.3-0.7)^{*}$ & \\
\hline
\end{tabular}

* Significant association $\mathrm{p}<0.05$; Binary Logistic Regression; OR adjusted by all variables; $\mathrm{OR}=$ odds ratio; $\mathrm{CI}=$ confidence interval; MW = minimun wage .

\section{Discussion}

The main results found in this study indicated a higher prevalence of women with osteoporosis, while absence of osteoporosis was more usual among married elderly people, with income above three minimum wages, with good health perception, who do not take medications and who had not suffered falls and near falls in the last semester. Women, elderly people who take more than two medications and who had ha falls in the last semester were 
more likely to have osteoporosis than their peers.

Regarding the prevalence, osteoporosis was frequent among females, as they were more likely to have the disease. According to the literature, this pathology is, in fact, more prevalent in women ${ }^{2,11-13}$. Postmenopausal women are more likely to develop osteoporosis due to the substantial drop in estrogen production, which makes older women vulnerable to this pathology ${ }^{14}$. According to one study, annual rates of bone loss after menopause are estimated to be 1.8 to $2.3 \%$ in the spine and 1.0 to $1.4 \%$ in the hip ${ }^{14}$. Epidemiological studies have shown that in the early postmenopausal years fractures of the wrist and spine are more incidental, whereas in older women, hip fractures become more common $^{14}$. According to Ki-Soo et $\mathrm{al}^{15}$, in Korea, the disease affects $7.5 \%$ of men over 50 years old against $37.3 \%$ of women, of whom about $15 \%$ will need medical treatment due to fractures caused by the disease ${ }^{2}$.

Marital status showed a significant correlation with the absence of osteoporosis; there was a lower proportion of married elderly women with a diagnosis of osteoporosis. This finding resembles the study of Lee et al. ${ }^{16}$ whose objective was to investigate whether the social support network of the elderly influenced the presence of osteoporosis ${ }^{15}$. Three types of support networks were measured: objective support, subjective support and use of support. The results of the study showed that elderly people with a larger social support network had a lower incidence of osteoporosis, as well as elderly people married and that lived with other people ${ }^{15}$. Another study suggested that being married could be beneficial for bone health. Korean elderly women who lived with their spouses had approximately 20\% lower prevalence of osteoporosis compared to women who did not live with partners ${ }^{16}$. Older married Australian men had a higher bone mineral content than those who lived alone ${ }^{17}$. Elderly individuals who were married had a significant difference in relation to the diagnosis of osteoporosis ${ }^{12}$.

Furthermore, the pathology seems to be associated with high mortality, socioeconomic stress ${ }^{2}$ and low schooling ${ }^{12}$. These findings allow us to infer that socioeconomic conditions, often linked to schooling level, lead wealthy individuals to have more access to health and nutrition conditions, and consequently lower development of osteoporosis.

The results of the present study show that the absence of falls in the last six months and no history of falls and near falls was associated with the absence of osteoporosis. Falls represent a predictor of poor health.
Elderly people who fall with frequency tend to be more prone to hospitalizations, social isolation, multimorbity, depression and mortality ${ }^{18,19}$. The study ${ }^{18}$ showed that osteoporosis is a factor that influences the occurrence of low energy traumas, such as falls. Among a total of 299 elderly people with history of falls, osteoporosis was present in $30.1 \%$ of those who reported one fall in the previous year and in $44.7 \%$ of those who reported 2 or more episodes of falls ${ }^{18}$. Osteoporosis not only predisposes the elderly person to falls, but also raises the risk of hip and femur fracture and consequent functional dependence ${ }^{20}$. It is worth bear in mind that the regression made in the present study showed that elderly people who had fallen in the last semester had a higher chance of having the disease.

The use of medications was negatively associated with the diagnosis of osteoporosis, that is, older people who used more than two medications were more likely to present the condition compared to those who did not use medications. This finding may be associated with the fact that elderly people with osteoporosis require drug treatment, as recommended by guidelines for the management of the disease. This leads us to infer that elderly patients with osteoporosis are unlikely to be free from the need to use medications ${ }^{3,21}$. One study pointed out that drug treatment has been effective in elderly patients and is able to reduce the risk of fracture ${ }^{22}$. However, according to the author, drugs destined to treat osteoporosis are not available for the entire population, and elderly people with higher education at higher purchasing power generally have more access to medications ${ }^{21}$. The lack of financial resources to attend consultations with medical specialists can also affect the therapeutic approach of the disease ${ }^{21}$. In contrast, the use of more than two medications may suggest the presence of comorbidities, which is also a risk factor for the development of osteoporosis ${ }^{4}$. Therefore, the use of medications seems to be linked to the diagnosis of osteoporosis.

Some limitations of the study should be emphasized, among them: non-observation of the diagnosis of osteopenia, which constitutes a potential risk factor for the development of osteoporosis; non-observation of the family history of osteoporosis, as scientific evidence indicates the hereditary nature of the pathology; failure to observe the use of hormone replacement drugs by women, which may reduce the incidence of osteoporosis; non-investigation of functionality and limitations in daily activities; non-investigation of the fear of falling, which is quite common among elder- 
ly people affected by osteoporosis. Future studies are needed to better understand the phenomena involved in the prevalence of osteoporosis among elderly people in the community. Another limitation of the study is that the use of binary regression procedures in this cross-sectional study may overestimate the associations.

It was concluded that sex, the amount of medications that the elderly regularly takes, and the history of falls are associated with the prevalence of osteoporosis in the elderly. It should be noted that women and elderly people who took more medications and who had a history of falls were more likely to have the disease. From a practical point of view, we highlight the importance of encouraging the practice of regular physical activity for the maintenance of physical capacities and muscular strength of the elderly, thus preventing falls, besides the importance of health protection to avoid the need of medications. Such care is even more relevant in the case of women because they are more likely to have osteoporosis.

\section{Conflict of interest}

The authors declare no conflict of interest

\section{Contribution of the authors}

Oliveira DV and Cavaglieri CR, participated in the initial study design and critical review of the text. Oliveira GVN and Silva DA, participated in data collection, literature search and writing. Pivetta NRS, participated in the writing. Nascimento Júnior JRA and Antunes MD, participated in the analysis of the data.

\section{References}

1. Zamboni M, Rossi AP, Fantin F, Zamboni G, Chirumbolo S, Zoico E, et al. Adipose tissue, diet and aging. Mech Ageing Dev. 2014;136(137):129-37.

2. Manini TM, Clark BC. Dynapenia and aging: an update. J Gerontol A Biol Sci Med Sci. 2012;67(1):28-40.

3. Janssen I, Heymsfield SB, Ross R. Low relative skeletal muscle mass (sarcopenia) in older persons is associated with functional impairment and physical disability. J Am Geriatr Soc. 2012;50(5):889-96.

4. Fernandez AL, Muñoz-García D, Touche RL. The level of physical activity affects the health of older adults despite being active. J Exerc Rehabil. 2016;12(3):194-201.

5. Cruz-Jentoft AJ, Baeyens JP, Bauer JM, Boirie Y, Cederholm T,Landi F,et al. Sarcopenia: European consensus on definition and diagnosis: Report of the European Working Group on Sarcopenia in Older People. Age Ageing. 2010;39(4):412-23.

6. Manini T. Development of physical disability in older adults. Curr Aging Sci. 2013;4(3):184-91.
7. Folstein MF, Folstein SE, McHugh PR. "Mini-mental state" A practical method for grading the cognitive state of patients for the clinician. J Psychiatr. 1975;2(3):189-98.

8. Brucki SMD, Nitrini R, Caramelli P, Bertolucci PHF, Okamoto IH. Sugestões para o uso do mini-exame do estado mental no Brasil. Arq Neuropsiquiatr. 2003;61(3B):777-81.

9. Matsudo S, Araújo T, Marsudo V, Andrade D, Andrade E, Braggion G. Questinário internacional de atividade f1sica (IPAQ): estudo de validade e reprodutibilidade no Brasil. Rev Bras Ativ Fís Saúde. 2001;6(2):5-18.

10. Mazo, GZ, Benedeti TRB. Adaptação do questionário internacional de atividade física para idosos. Rev Bras Cineantropom Desempenho Hum. 2010;12(6):480-4.

11. Raichlen DA, Alexander GE. Adaptive Capacity: An Evolutionary Neuroscience Model Linking Exercise, Cognition, and Brain Health. Trends Neurosci. 2017;40(7):408-21.

12. Petersen RC. Mild cognitive impairment as a clinical entity and treatment target. Arch Neurol. 2004;62(7):1160-3.

13. Winblad B, Palmer K, Kivipelto M, Jelic V, Fratiglioni L. Mild cognitive impairment - beyond controversies, towards a consensus : report of the International Working Group on Mild Cognitive Impairment. J Intern Med. 2004;9:240-6.

14. Gligoroska J, Manchevska S. The Effect of Physical Activity on Cognition - Physiological Mechanisms. Mater Socio Medica. 2012;24(3):198-202.

15. Ribeiro AS, Avelar A, Schoenfeld BJ, Ritti Dias RM, Altimari LR, Cyrino ES. Resistance training promotes increase in intracellular hydration in men and women. Eur J Sport Sci. 2014;14(6):578-85.

16. Lee I-M, Shiroma EJ,Lobelo F,Puska P,Blair SN,Katzmarzyk PT. Impact of Physical Inactivity on the World's Major NonCommunicable Diseases. Lancet. 2012;380(9838):219-29.

17. Nagamatsu LS, Handy TC, Hsu CL, Voss M, Liu-Ambrose $\mathrm{T}$. Resistance training promotes cognitive and functional brain plasticity in seniors with probable mild cognitive impairment. Arch Intern Med. 2012;172(8):666-8.

18. Nascimento CMC, Pereira JR, Pires de Andrade L, Garuffi M, Ayan C, Kerr DS, et al. Physical exercise improves peripheral BDNF levels and cognitive functions in mild cognitive impairment elderly with different bdnf Val66Met genotypes. J Alzheimers Dis. 2015;43(1):81-91.

19. Coelho FM, Pereira DS, Lustosa LP, Silva JP, Dias JM, Dias $\mathrm{RC}$, et al. Physical therapy intervention (PTI) increases plasma brain-derived neurotrophic factor (BDNF) levels in non-frail and pre-frail elderly women. Arch Gerontol Geriatr. 2012;54(3):415-20.

20. Bamidis PD, Fissler P, Papageorgiou SG, Zilidou V, Konstantinidis EI, Billis AS, et al. Gains in cognition through combined cognitive and physical training: The role of training dosage and severity of neurocognitive disorder. Front Aging Neurosci. 2015;7(152):1-15.

21. Hillman CH, Erickson KI, Kramer AF. Be smart, exercise your heart: exercise effects on brain and cognition. Nat Rev Neurosci. 2008;9(1):58-65.

22. Erickson KI, Weinstein AM, Lopez OL. Physical activity, brain plasticity, and Alzheimer's disease. Arch Med Res. 2012;43(8):615-21.

Received: $16 / 11 / 2018$ Approved: 09/04/2019

Quote this article as:

Oliveira DV, Oliveira GVN, Silva DA, Pivetta NRS, Antunes MD, Nascimento Júnior JRA, Cavaglieri CR. Prevalence of osteoporosis and its associated factors in older adult's users of the Primary Health Care. Rev Bras Ati Fis Saude. 2018.23:e0055. DOI: 10.12820/rbafs.23e0055. 